of IL-10 (as immunosupressive cytokine) and IL-6 (which takes part in myoproteosis degradation) serum levels can restore immune cells activity. It was correlated with increasing the leukocyte integrins expression. Down regulation of serum IL-6 and IL-10 cytok- ines in males of CBA inbred mice with high frequency of spontaneous hepatocarcinomas is considered to reduce antitumour antibodies production (which cover tumor cells antigens and diminish immune cells activity) as well as cachexia symptoms.

\title{
NUTRACEUTICALS FROM BEETROOT POMACE EXTRACT WITH ANTIOXIDANT AND HEPATOPROTECTIVE EFFECTS
}

\section{(드anadanović-Brunet Jasna ${ }^{1}$, Ćebović Tatjana², Vulić Jelena ${ }^{1}$, Ćetković Gordana ${ }^{1}$, Djilas Sonja $^{1}$}

${ }^{1}$ Faculty of Technology, University of Novi Sad, Bulevar cara Lazara 1, 21000 Novi Sad, Serbia

${ }^{2}$ Faculty of Medicine, Clinical centre of Vojvodina, Hajduk Veljkova 3, Novi Sad, Serbia

The beetroot pomace (BPE), residue from the juice processing, is promising source of bioactive compounds with antioxidant, hepatoprotective and antitumor properties. The aim of this research was to investigate the antioxidant activity of BPE and its effect on biochemical parameters of oxidative stress evaluated in liver homogenate of rats. The antioxidant activity of BPE, including reducing power and DPPH free radical scavenging activity were determined spectrophotometrically. The effects of BPE on several biochemical parameters of oxidative stress were evaluated in liver homogenate of rats treated with $\mathrm{CCl}_{4}$ as a free radical generator: LPx intensity, content of GSH and activities of GSH-Px, GR, Px, XOD and CAT. BPE was able to scavenge DPPH radicals $\left(E_{50}{ }^{D P P H}=3.4 \mu \mathrm{g} / \mathrm{ml}\right)$. The reducing power of BPE increased with increasing the concentration. The BPE, combined with $\mathrm{a} \mathrm{Cl}_{4}$, expressed a clear and dose-dependent suppressive effect against lipid peroxidation in liver homogenate. Simultaneous application of extract and $\mathrm{CCl}_{4}$ has led to a significant decrease in GSH-Px levels, keeping the GSH content in liver homogenate close to physiological level. Similar impact on GR activity has been observed in liver of the animals. The catalase activity was decreased after treatment with $\mathrm{BPE}$ and $\mathrm{CCl}_{4}$ Similar influence on hepatic Px activity has been also observed. Although $\mathrm{CCl}_{4}$ does not alter the activity of hepatic XOD certain increase of XOD activity has been measured after addition of BPE. Obtained results demonstrated that the beetroot pomace extract might possess a specific antioxidant potential, suggesting that it might be used not only as a hepatoprotective agent, but as an active agent in treatment of other disorders caused by oxidative stress.

\section{VALORISATION OF ANTIOXIDANT AND CELL GROWTH ACTIVITIES OF TOMATO WASTE LIPOPHILIC EXTRACTS}

\section{(C) Ćetković Gordana ${ }^{1}$, Savatović Sladjana1, Čanadanović-Brunet Jasna1, ${\text { Djilas Sonja }{ }^{1}, \text { Mandić Anamarija }^{2} \text {, Četojević-Simin Dragana }}^{3}$}

\author{
${ }^{1}$ Faculty of Technology, University of Novi Sad, Bulevar Cara Lazara 1, 21000 Novi Sad, Serbia \\ ${ }^{2}$ Institute for Food Technology in Novi Sad, University of Novi Sad, Bulevar Cara Lazara 1, 21000 Novi Sad, Serbia \\ ${ }^{3}$ Oncology Institute of Vojvodina, Institutski put 4, 21204 Sremska Kamenica, Serbia
}

Tomato, fresh and its products, possess a high nutritional value, due to content of different types of antioxidants: carotenoids, polyphenolics, vitamin $\mathrm{C}$ and vitamin E. According to the fact that different valuable compounds remained in the waste from tomato juice processing, the aim of this research was to investigate the antioxidant and cell growth activities of tomato waste lipophilic extracts (obtained from genotypes - Bačka and Saint Pierre). The lycopene and $\beta$-carotene in tomato waste extracts were identified and quantified by HPLC method by matching their retention times (RT) and on-line ultraviolet (UV) spectra with those of stan- dards. The antioxidant activity of extracts were investigated by measuring 2,2-diphenyl-1-picrylhydrazyl (DPPH) radical scavenging activity by spectrophotometric method. The cell growth activity was measured using the sulforhodamine B colorimetric assay on human cancer HeLa (cervix epitheloid carcinoma) and MCF7 (breast adenocarcinoma) cell lines. The Baka waste extract contained higher st content of lycopene $(13.6 \pm 0.1 \mathrm{mg} / \mathrm{g})$ and $\beta$-carotene $(12.0 \pm 0.3 \mathrm{mg} / \mathrm{g})$. The extracts were able to scavenge DPPH radical and higher antioxidant activity, expressed as $\mathrm{IC}_{50}{ }^{\mathrm{DPPH}}$ value, was obtained in the case of the Bačka waste extract 